\title{
Rootstock Effect on Physico-Chemical and Nutritional Quality of Mandarin 'Clemenules' during the Harvest Season
}

\author{
Julia Morales ${ }^{1} \mathbb{D}$, Almudena Bermejo ${ }^{2} \mathbb{D}$, Pilar Navarro ${ }^{1}$ and Alejandra Salvador ${ }^{1, *}$ \\ 1 Postharvest Department, Instituto Valenciano de Investigaciones Agrarias, 46113 Valencia, Spain; \\ morales_jul@gva.es (J.M.); navarro_pillat@gva.es (P.N.) \\ 2 Citriculture Department, Instituto Valenciano de Investigaciones Agrarias, 46113 Valencia, Spain; \\ bermejo_alm@gva.es \\ * Correspondence: salvador_ale@gva.es; Tel.: +34-963-424-000; Fax: +34-963-424-001
}

Received: 7 August 2020; Accepted: 3 September 2020; Published: 8 September 2020

\begin{abstract}
This study reports the influence of eight rootstocks ('Carrizo' (CC), 'C-35' (C35) 'Cleopatra' (CL), 'Volkameriana' (VK), 'Macrophylla' (M), 'Forner-Alcaide 5' (FA5), 'Forner-Alcaide 13' (FA13) and 'Forner-Alcaide V17' (V17)) on the physico-chemical and nutritional quality of 'Clemenules' mandarins at three harvest times during two seasons. Fruit quality parameters were influenced by rootstocks, and this effect was mostly harvest time -dependent. External color was overall influenced by rootstocks upon the first harvest. FA13 and C35 induced a breakthrough in color change, while V17 brought about the greatest color increase. CL and V17 initially delayed the fruit maturity index. In the last harvest, while CL had one of the highest maturity indices, V17 exhibited the lowest as acidity was maintained as harvest advanced. The CC and M fruit had the highest and lowest sucrose content, respectively. The highest glucose and fructose contents in fruit were induced by V17, FA5 and CC. The highest citric acid content was displayed by V17 in all the harvests. The FA13, C35 and VK fruit exhibited the highest malic acid content. The effect that rootstock exert on ascorbic acid and flavonoid content depends on the studied season. The results reveal the importance of conducting studies during different seasons to obtain robust results.
\end{abstract}

Keywords: ascorbic acid; flavonoids; organic acids; sugar; maturity index; firmness; color

\section{Introduction}

Rootstocks are frequently used in citriculture to improve crop adaptation to different biotic and abiotic conditions by regulating the uptake and movement of water and nutrients among plant organs [1-3]. The rootstock can also influence fruit quality parameters [4] such as color [5,6] or maturity index $[7,8]$ and nutritional juice parameters, such as individual sugars and organic acids $[9,10]$, phenolic compounds [1,11] or vitamin C [12]. The effects of rootstock strongly depend on the rootstock-scion interaction.

Most studies that have addressed the effect of rootstock on citrus fruit quality have been conducted on a single point of maturity, and very few studies consider if these effects remain throughout the season $[13,14]$. It is important to highlight this aspect for those varieties with a long harvest period. This is the case of early mandarins in the Mediterranean Region, where citrus fruit reaches commercial internal maturity before the color change from green to orange takes place. Thus fruit can be harvested at the beginning of the season, with no full external coloration, to be submitted to ethylene degreening treatment, which induces chlorophyll degradation and carotenoid biosynthesis [15,16]. However, fruit can also be harvested later when it has completed typical external coloration halfway through or at the end of the season. 
The effect of rootstock on internal quality parameters, such as acidity and sugar contents is crucial because it can not only determine harvest time, but can also influence the maintenance of these parameters throughout harvest. Moreover, the rootstock effect on external color can bring about advanced harvests, which is relevant at the beginning of the season, especially in early varieties.

'Clemenules' clementine (Citrus clementina Hort. ex Tan.) is considered one of the most important early mandarins that is harvested from early September to late December. Like most mandarins in the Mediterranean Region, this cultivar reaches internal maturity before full coloration. Thus at the beginning of the season, it is usually submitted to degreening ethylene treatment to enhance external color.

This study aims to characterize the physico-chemical and nutritional quality of 'Clemenules' mandarins grafted onto eight rootstocks at three commercial harvest times during two seasons.

\section{Materials and Methods}

\subsection{Plant Material}

Experiments were conducted with 'Clemenules' mandarins taken from 12-year-old trees grafted onto eight different rootstocks: 'Carrizo' (CC) and 'C-35' (C35) citranges, 'Cleopatra' mandarin (CL), 'Volkameriana' (VK), 'Macrophylla' (M) and three hybrid selections, 'Forner-Alcaide 5' (FA5), 'Forner-Alcaide 13' (FA13); 'Forner-Alcaide V17' (V17), obtained from the rootstock breeding program carried out at the Instituto Valenciano of Investigaciones Agrarias (IVIA) (Table 1). They are cultivated in an experimental plot of Anecoop S. Coop. located in Museros, Valencia $\left(39^{\circ} 34^{\prime} 45.6^{\prime \prime} \mathrm{N}, 0^{\circ} 21^{\prime} 48.8^{\prime \prime} \mathrm{W}\right)$ with sandy loam soil (sand $65.28 \%$, silt $18 \%$ and clay $16.72 \%$ ). This orchard had EC $1: 5$ of $0.344 \mathrm{dS} \mathrm{m}^{-1}$ $\left(25^{\circ} \mathrm{C}\right)$ and a $\mathrm{pH}$ of 7.8 .

Table 1. Description of the rootstocks tested for 'Clemenules' mandarin.

\begin{tabular}{ccl}
\hline Rootstock & Abbreviation & \multicolumn{1}{c}{ Botanical Name } \\
\hline Forner-Alcaide 13 & FA13 & Citrus reshni $\times$ Poncirus trifoliata (L.) Raf. no 13 \\
Forner-Alcaide 5 & FA5 & Citrus reshni $\times$ Poncirus trifoliata (L.) Raf. no 5 \\
Citrange Carrizo & CC & Citrus sinensis (L.) Osbeck $\times$ Poncirus trifoliata (L.) Raf. \\
C-35 & C35 & Citrus sinensis (L.) Osbeck $\times$ Poncirus trifoliata (L.) Raf. (Hybrid) \\
Cleopatra Mandarin & CL & Citrus reshni Hort. Ex Tan \\
Macrophylla & M & Citrus macrophylla Wester \\
Volkameriana & VK & Citrus volkameriana Ten. \& Pasq. \\
Forner-Alcaide V17 & V17 & Citrus volkameriana Ten \& Pasq. $\times$ Poncirus trifoliata (L.) Raf. no V17 \\
\hline
\end{tabular}

The study was carried out during two seasons (2016 and 2018) with fruit harvested at three different times. The first harvest was performed when the maturity index (MI) of fruit came close to 7, MI value established as the minimum to commercialize mandarin fruit [17]. The second and third harvests took place 30 and 60 days after the first harvest, respectively. The harvest dates were 28 September, 28 October and 28 November in the first season, and 20 September, 20 October and 20 November in the second season (2018).

At each harvest moment, 60 fruits were picked from three previously selected trees of each rootstock and transferred to the laboratory at IVIA where the following analyses were carried out: color, firmness, total soluble solids, acidity, maturity index, individual sugar concentrations, organic acid concentrations, flavonoid concentrations, ascorbic acid concentration.

\subsection{External and Internal Quality Parameters Measurements}

External fruit peel color was measured by a Minolta colorimeter (model CR-300, Minolta Co. Ltd., Osaka, Japan) with 15 fruits per lot by taking two measurements from the opposite equatorial sides of each fruit. The mean values for the ' $L$ ', ' $a$ ' and ' $b$ ' Hunter parameters were calculated with each fruit and expressed as the Citrus Color Index (CCI) $(\mathrm{CCI}=1000 \mathrm{a} / \mathrm{Lb})[18]$. 
Firmness measurements were taken by a Universal Testing Machine (model 3343, Instron Limited, Buckinghamshire, UK) with 15 fruits per lot. The results were expressed as the percentage of millimeters of fruit deformation that resulted from a $10 \mathrm{~N}$ force on the longitudinal axis at constant speed.

In each fruit lot, three samples of five fruits each were squeezed using an electric juice extractor with a rotating head $\left(\right.$ Lomi $^{\circledR}$, Model 4, Lorenzo Miguel, S.L., Madrid, Spain). Titratable acidity (TA) was determined by titration with $0.1 \mathrm{~N} \mathrm{NaOH}$ solution, with phenolphthalein as the indicator, and expressed as g citric acid/L of juice. The total soluble solids content (TSS) in juice was measured by a digital refractometer (Atago PR-1, Atago Co., Ltd., Tokyo, Japan). Data were expressed as ${ }^{\circ}$ Brix. The maturity index (MI) was calculated as the TSS/TA ratio.

\subsection{Biochemical Measurements}

Part of the juice from each sample, obtained as described above, was transferred after squeezing fruit into $2 \mathrm{~mL}$ eppendorf tubes and stored at $-20{ }^{\circ} \mathrm{C}$ for the biochemical analysis.

The extraction method and HPLC analysis of sugars were the same as a previously described procedure [19]. Fructose, glucose and sucrose sugars were identified by comparing their retention time to a standard (obtained from Sigma, Co., Barcelona, Spain). These sugars were quantified with an external calibration curve. The results were expressed as $\mathrm{g} / \mathrm{L}$.

The extraction and analysis of organic acids were carried out according to the previously described method [19]. Compounds were analyzed by HPLC-DAD and HPLC-MS under electrospray ion negative conditions. An ICSep ICE-COREGEL 87H3 column (Transgenomic) was used in an isocratic mobile phase of $0.1 \% \mathrm{H}_{2} \mathrm{SO}_{4}$ solution at the $0.6 \mathrm{~mL} / \mathrm{min}$ flow rate. The injection volume was $5 \mu \mathrm{L}$. Standard compounds were supplied by Sigma (Sigma Co., Barcelona, Spain). The results were expressed as $\mathrm{g} / \mathrm{L}$.

The main flavonoids were extracted following a previously described procedure [20], with some modifications to adapt the method to a microliter format [19]. Narirutin, hesperidin and didymin were analyzed by HPLC-DAD and HPLC-MS under electrospray ion positive conditions according to formerly described method [21]. Standards were obtained from Extrasynthesis (Genay, France), Sigma (Sigma Co., Barcelona, Spain) and ChromaDex (Irvine, CA, USA). The results were expressed as $\mathrm{mg} / 100 \mathrm{~mL}$.

Total vitamin C was extracted with the previously reported method [22]. DL-dithiothreitol (DTT) was used as the reducing reagent of dehydroascorbic acid to ascorbic acid. Ascorbic acid quantification was performed by HPLC-DAD, as previously described [19]. L-ascorbic acid was obtained from Sigma (Sigma Co., Barcelona, Spain) and DTT came from Fluka (Sigma Co., Barcelona, Spain). The results were expressed as $\mathrm{mg} / 100 \mathrm{~mL}$.

The HPLC analyses were performed with an Alliance liquid chromatographic system (Waters, Barcelona, Spain), equipped with a 2695 separation module, a 2996 photodiode array detector and a ZQ2000 mass detector. Samples were detected at $5^{\circ} \mathrm{C}$. The column temperature was either $25^{\circ} \mathrm{C}$ or $35^{\circ} \mathrm{C}$. The sugars analysis was carried out by a Waters 515 HPLC pump with 2414 refractive index detector and a $20 \mu \mathrm{L}$ loop Rheodyne injector. Data were acquired and processed by the Empower 2 software (Waters, Spain). Grade solvents and Milli-Q water were used in all biocompound HPLC analyses.

\subsection{Statistical Analysis}

Statistical procedures were performed using statistical software (Statgraphics Centurion XVII.II software; Manugistics, Rockville, NY, USA). All the data were subjected to an analysis of variance based on two factors (harvest time $\times$ rootstock) for each season. Moreover for each harvest, the rootstock effect was studied by one way Anova. The mean values were compared by the least significant difference test (LSD) $(p \leq 0.05)$. 


\section{Results and Discussion}

\subsection{Effect of Rootstock on External Color, Firmness, Total Soluble Solids and Acidity}

An effect of rootstock on the main pigments in citrus peel was reported previously by Cano and Bermejo [23]. In the present study the external color was influenced by both harvest and rootstock and the interaction between these two factors was significant (Table 2). During both studied seasons, upon the first harvest FA13 and C-35 fruit had the highest color index (Figure 1A), close to -12 , while the other fruit obtained color index values from -18.0 to -15.5 . At the second harvest, the major increase was exhibited by the V17 fruit, which had the highest values, -3.69 and 0.99 at first and second season, respectively. At this harvest, the lowest values were presented by the CL fruit. At the third harvest, the differences among rootstocks were less pronounced when color values came to $7.45-13.35$ in the first season and 12.88-16.20 in the second one. C-35 fruit had the lowest values during both seasons. Similarly to what we herein observed, a major rootstock effect on the external color of 'Ruby Red' at the beginning of the season has been reported, with scarcely any differences as season advanced [5].

Table 2. $p$-values $(p \leq 0.05)$ of rootstock (A), harvest (B) factors and rootstock-harvest interaction (AB) of the parameters measured of 'Clemenules' mandarins grafted onto eight different rootstocks. * Significant at $p \leq 0.05$.

\begin{tabular}{|c|c|c|c|c|c|c|}
\hline & \multicolumn{3}{|c|}{ 1st Season } & \multicolumn{3}{|c|}{ 2nd Season } \\
\hline & A: Rootstock & B: Harvest & $A B$ & A: Rootstock & B: Harvest & $\mathrm{AB}$ \\
\hline Color & 0.0000 * & $0.0000 *$ & 0.0000 * & 0.0000 * & 0.0000 * & 0.0000 * \\
\hline Firmness & 0.0000 * & $0.0000 *$ & 0.0013 * & $0.0000 *$ & $0.0000 *$ & 0.0073 * \\
\hline TSS & 0.0000 * & $0.0000 *$ & 0.2379 & 0.0000 * & $0.0001 *$ & 0.1971 \\
\hline Acidity & 0.0000 * & $0.0000 *$ & 0.0001 * & 0.0000 * & 0.0000 * & 0.0001 * \\
\hline MI & 0.0000 * & $0.0000 *$ & $0.0046^{*}$ & 0.0000 * & 0.0083 * & $0.0006^{*}$ \\
\hline \multicolumn{7}{|l|}{ Individual Sugars } \\
\hline Sucrose & 0.0094 * & $0.0000 *$ & 0.7684 & $0.0011 *$ & $0.0000 *$ & 0.0133 * \\
\hline Glucose & 0.0000 * & 0.0000 * & 0.0038 * & 0.0000 * & 0.2197 & 0.1088 \\
\hline Fructose & 0.0000 * & 0.0000 * & 0.3480 & 0.0000 * & 0.0594 & 0.3616 \\
\hline \multicolumn{7}{|l|}{ Organic Acids } \\
\hline Citric Acid & 0.0000 * & 0.0000 * & 0.0203 * & 0.0000 * & 0.0000 * & 0.0000 * \\
\hline Malic Acid & $0.0000 *$ & $0.0000 *$ & $0.0080 *$ & $0.0000 *$ & $0.0001 *$ & 0.1018 \\
\hline Succinic Acid & 0.0000 * & $0.0000 *$ & 0.0509 & 0.0001 * & 0.0000 * & 0.0602 \\
\hline $\begin{array}{l}\text { Ascorbic Acid } \\
\text { Flavonoids }\end{array}$ & $0.0002 *$ & 0.0004 * & 0.1134 & $0.0000 *$ & 0.3626 & 0.7735 \\
\hline Hesperidin & 0.1401 & 0.0719 & 0.1624 & 0.0000 * & $0.0000 *$ & 0.0503 \\
\hline Narirutin & 0.0028 * & 0.4811 & 0.8620 & 0.0000 * & 0.0000 * & 0.1277 \\
\hline Didymin & 0.0017 * & 0.1447 & 0.7960 & 0.2791 & 0.0000 * & 0.7972 \\
\hline
\end{tabular}

Firmness is an important fruit quality parameter, but is not included in the current citrus quality standards. Low fruit firmness can act as an important limitation for citrus fruit commercialization. Indeed, in citrus rootstock breeding programs, enhancing fruit firmness remains a challenge given its importance for fruit quality, especially when fruit is to be exported [24,25]. In the present study, an influence of both rootstock and harvest time on fruit firmness was detected during both seasons, existing a significant interaction between these two factors (Table 2). A rise in the deformation values with advanced harvest time was found, and this firmness loss was more marked during the third harvest (Figure 1B). The effects of rootstocks during both seasons were similar. FA13 and C-35 induced the highest firmness throughout the study while V17 obtained the lowest firmness values. Must be taken into account that all the fruit had commercial firmness values throughout the studied period, with deformation percentage values under $6.5 \%$. Although very few references exist about limits of 
firmness values in citrus fruit for its fresh commercialization, there are reports in fruit to be exported about deformation values having to be lower than $10 \%$ in mandarins [26].

A
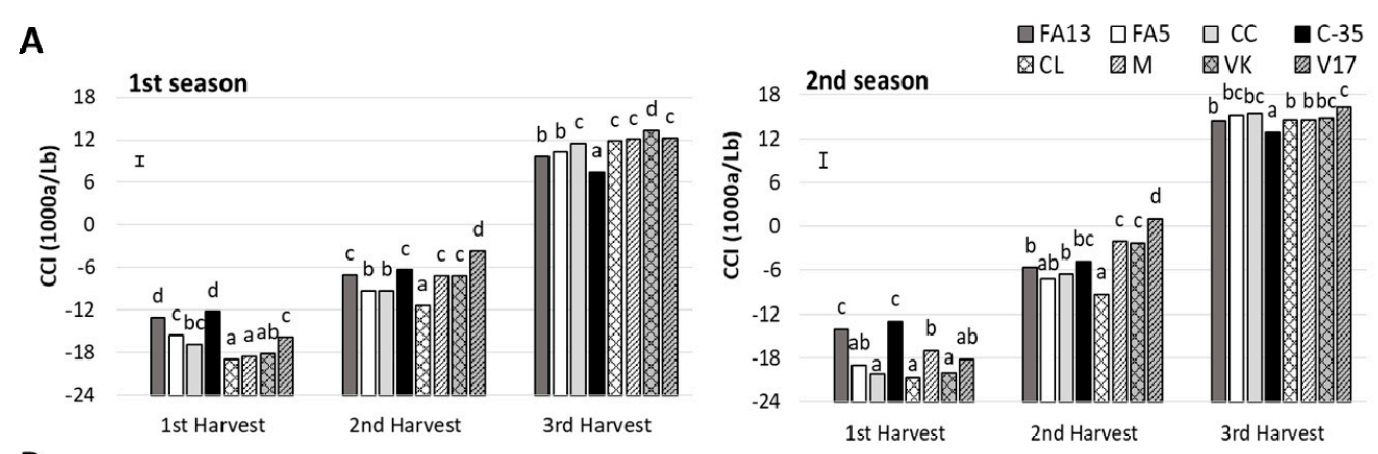

B
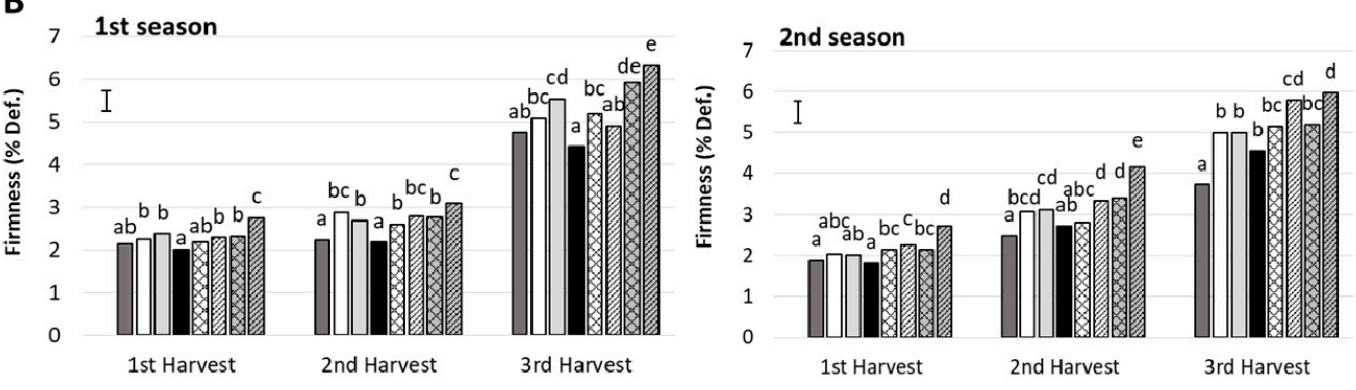

Figure 1. Citrus color index (CCI) (A) and firmness (B) of the 'Clemenules' mandarin grafted onto the eight studied rootstocks at three harvest times during two seasons. Vertical bar in each season represents the least significant difference (LSD) intervals $(p \leq 0.05)$ (interaction harvest-rootstock). Different letters above bars indicate significant differences among rootstocks at each harvest time $(p \leq 0.05)$.

The rootstock influence on sugars and acid content has been related to the inherent rootstock effect on plant water relations [27-29]. In the present study, TSS content increased with harvest time during both seasons (Figure 2A), as previously reported for most citrus fruit [30]. TSS content was strongly influenced by rootstocks and harvest time and no harvest-rootstock interaction was detected (Table 2). During the first season, the TSS content ranged was close to 11.0 in FA13, C-35, CL, M and VK with values close to 12.0 for FA5, CC, and V17. During the following harvests, the most important increase took place in the $\mathrm{CC}$ fruit, which had the highest values, $12.9^{\circ}$ Brix and $13.5^{\circ}$ Brix at second and third harvest, respectively. The lowest TSS values during the third harvest, close to $12.0^{\circ} \mathrm{Brix}$, were for M. During the second season, although the TSS values were lower than those recorded during the first one in all the harvests, the highest values were found for CC. The same effect of CC on TSS contents has been reported by Emmanouilidou and Kyriacou [14], who observed that 'Lane Late' and 'Delta' oranges grafted onto Carrizo Citrange had the highest TSS content than other four rootstocks.

During both seasons, at the first harvest, acidity ranged from values close to $2 \mathrm{~g}$ citric acid/L for CL to values near 1.5 in $\mathrm{M}$ (Figure 2B). The differences among rootstocks diminished as harvest advanced. The most marked descent in fruit acidity was detected in CL, between the first and second harvests. At third harvest and for both seasons, the V17 fruit maintained higher acidity levels than the other fruit, $1.01 \mathrm{~g}$ of citric acid/L. In other clementine mandarins, such as 'Clémentine de corse', a decrease of the acidity content with the fruit maturation was also observed [31].

The maturity index (MI) was represented in Figure 2C. All values were in agreement with other mandarin cultivars during harvest season such as 'Fina', 'Loretina' and 'Arrufatina' clementine mandarins [32]. In this study, a effect rootstock was found, and the differences among rootstocks depended on harvest time, along with a significant harvest-rootstock interaction (Table 2). During both seasons for the first harvest, all the fruit exceeded the minimum commercial MI value of 7.0, except for CL and V17 due to high acidity. With MI above 7.0, clementine mandarins can be submitted to 
degreening treatment. Nevertheless, it is noteworthy that degreening treatment duration depends on the initial external color, and short duration is recommended to avoid any disorders associated with this treatment [33]. Thus according to external color, FA13 and C-35, with a CCI close to -12 , could be subjected to shorter degreening treatments than the other fruit, which is relevant from a commercial point of view.

A

A
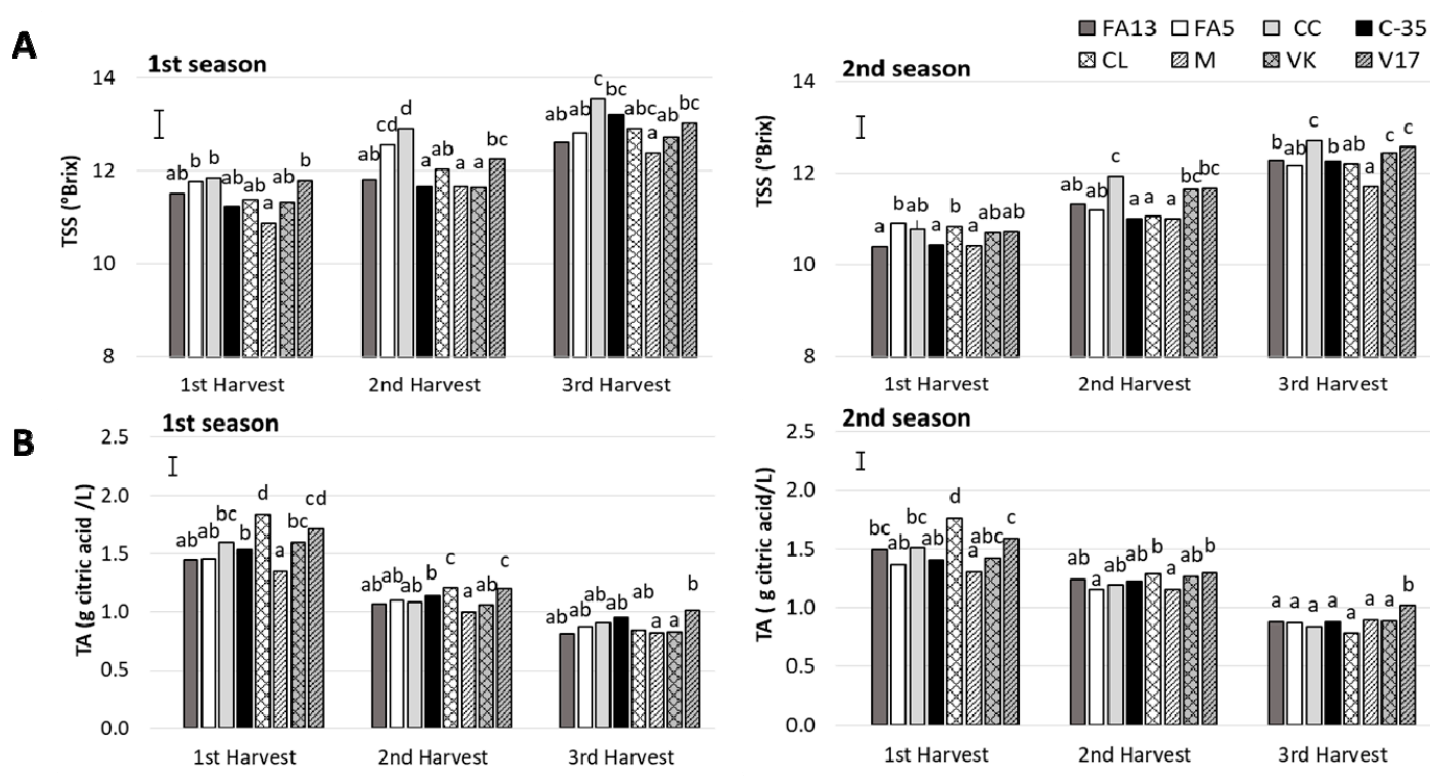

C

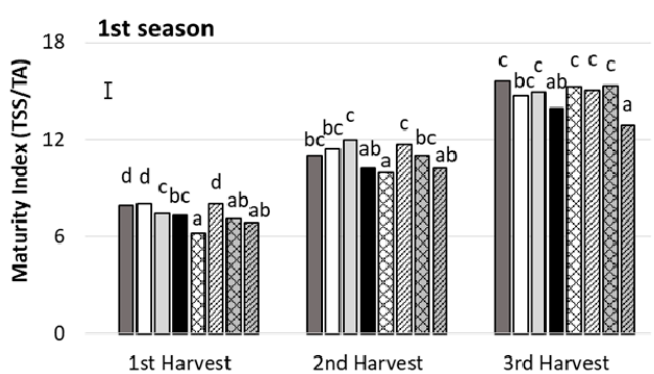
18

2nd

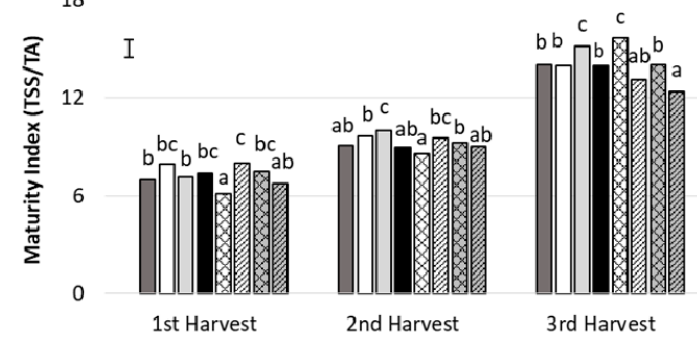

Figure 2. (A) Total soluble solids (TSS), (B) acidity (TA) and (C) Maturity Index (MI) of the 'Clemenules' mandarin grafted onto the eight studied rootstocks at three harvest times during two seasons. Vertical bar in each season represents the least significant difference (LSD) intervals $(p \leq 0.05)$ (interaction harvest-rootstock). Different letters above bars indicate significant differences among rootstocks at each harvest time $(p \leq 0.05)$.

Although the CL fruit had the lowest MI values during the first and second harvests, this fruit in the third harvest gave one of the highest MI values. This was due to this fruit's major acidity loss compared to other rootstocks. Conversely, the V17 fruit had the least MI increase as harvest advanced, with the lowest values that came close to 12.5 during the last harvest. This is related to acidity being maintained as harvest advanced. Previous studies also found the lowest MI values in V17 compared to other rootstocks [11]. Nevertheless, it is noteworthy that this effect was observed only during the third harvest in the present study, without no major differences found to the other rootstocks studied during the first and second seasons.

\subsection{Rootstock Effect on Individual Sugars, Organic Acids, Vitamin $C$ and Flavonoids}

Sugar composition was determined and three sugars were quantified (Figure 3). The predominant sugar was sucrose, followed by fructose and glucose, with values falling within the range reported previously for other clementine mandarin [32]. 

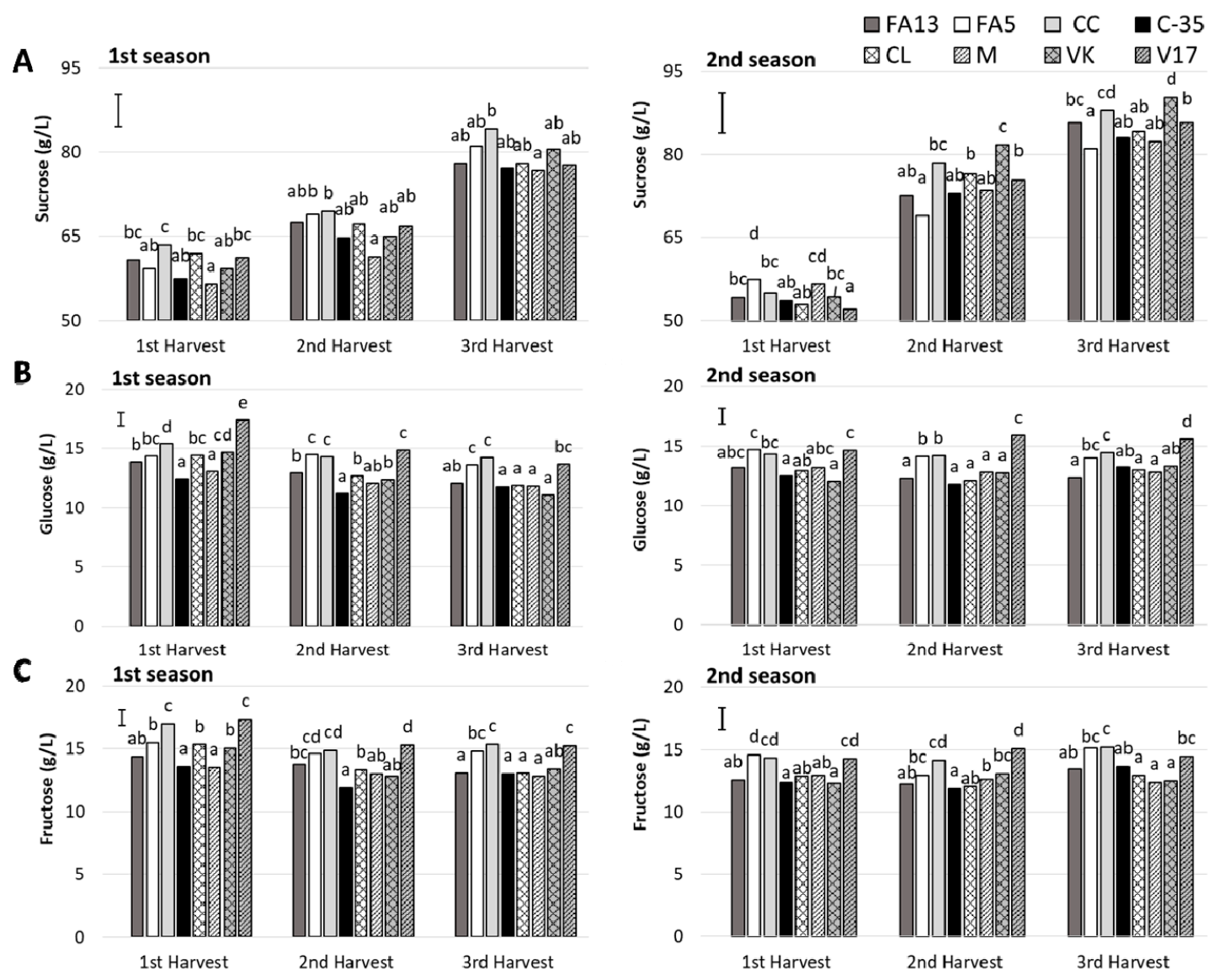

Figure 3. Individual sugars (A: sucrose; B: glucose; C: fructose) of the 'Clemenules' mandarin grafted onto the eight studied rootstocks at three harvest times during two seasons. Vertical bar in each season represents the least significant difference (LSD) intervals $(p \leq 0.05)$ (interaction harvest-rootstock). Different letters above bars indicate significant differences among rootstocks at each harvest time $(p \leq 0.05)$.

During the first season, sucrose content rose from 56.49-63.52 g/L at first harvest to 76.69-84.23 g/L at third harvest. The differences among rootstocks were similar for the three harvests (no harvest-rootstock interaction was detected) (Table 2). The CC fruit had the highest sucrose content and the lowest values went to the $\mathrm{M}$ fruit. During the second season, sucrose values were higher and ranged from 52.05 to $57.45 \mathrm{~g} / \mathrm{L}$ for the first harvest and from 81.01 to $90.30 \mathrm{~g} / \mathrm{L}$ for the third. In this case, the rootstock influence was harvest-dependent. In general, the rootstocks that induced the highest sucrose content were $\mathrm{CC}$ and VK, and no differences with FA13 appeared during the third harvest. No remarkable differences were found among the remaining rootstocks.

Glucose content ranged from 11.06 to $17.42 \mathrm{~g} / \mathrm{L}$ during both seasons. A general decrease as harvest advanced took place during the first season, while no harvest time influence was detected for the second season. Rootstock effect was observed during the two seasons with a harvest-rootstock interaction at the first season (Table 2). During both seasons, V17 was the rootstock that presented fruit with higher glucose contents, followed by FA 5 and CC. No main differences were observed among the other rootstocks.

Similarly to that observed for glucose, during the first season fructose content tended to lower with harvest time, and its values ranged from 13.53-17.38 g/L at first harvest to $12.83-15.36 \mathrm{~g} / \mathrm{L}$ at third, while no differences were shown for the second season as harvest advanced (values from 11.85 to $15.22 \mathrm{~g} / \mathrm{L}$ ). During both seasons, the highest fructose values were for the FA5, CC and V17 fruit. The other rootstocks showed no major differences between them. 
The increase of TSS with harvest advance as described above was due to the increase of sucrose content. So, CC lead to fruit with the highest TSS and also induced the highest sucrose content. On the other hand, the higher increase of sucrose content respect to the other individual sugars with harvest advance has been previously reported in other mandarin cultivars [34].

Organic acid profile was determined and three acids (citric acid, malic acid and succinic acid) were quantified (Figure 4), all of which exhibited similar values to those reported in literature for clementine mandarins and other citrus fruits [32]. The predominant organic acid was citric acid, followed by malic and succinic acid, respectively. Citric acid values (Figure 4A) for the first season fell within the 9.61-16.48 $\mathrm{g} / \mathrm{L}$ range for the first harvest and the 4.63-7.50 $\mathrm{g} / \mathrm{L}$ range for the last harvest. The drop in citric acid levels during ripening period has been also observed in 'Comune' and 'Tardivo' clementine mandarins [35]. These values were higher during the second season and ranged from 16.90-23.24 $\mathrm{g} / \mathrm{L}$ to 7.85-10.32 g/L for the first and third harvest, respectively. During both seasons, an important rootstock effect was found and it depended on harvest time (Table 2). The differences among rootstocks decreased as harvest advanced, which coincided with the drop in acidity. The V17 fruit stood out for having the most citric acid, which was observed for both seasons. It was also outstanding that CL at first harvest and during both studied seasons, had similar values to V17, which coincided with the high titratable acidity values mentioned above. Previous studies have reported that FA13 displays the lowest citric acid levels in 'Clemenules' mandarins than other rootstocks [11]. Nevertheless, in the present study, this was observed only during the first season, which indicates the importance of conducting studies at different maturity stages.

The second most relevant acid was malic acid (Figure 4B) which, unlike the other analysed organic acids, increased during the study period. During the first season, the effect of rootstock was harvest time dependent (Table 2). The amount of malic acid ranged from 1.33 to $1.71 \mathrm{~g} / \mathrm{L}$ for the first harvest. In all cases, a gradual increase was observed during the following harvests until values ranged from 2.74 to $3.45 \mathrm{~g} / \mathrm{L}$ in the third harvest. During the two first harvests, FA13 had the highest malic acid values. Nevertheless, at third harvest, when all the fruit significantly increased, the maximum values went to C35, with no differences with FA13 and VK. During the second season, a significant increase was observed from the first to the second harvest, with no major changes taking place during the last one. Similarly to that observed during the first season, FA13, C35 and VK had the highest values but in this case, this took place throughout the study period.

For succinic acid concentration (Figure 4C), major differences were observed between both studied seasons, and values were much lower during the first season, especially at first and second harvests. A marked rootstock influence was observed. During the second season, the succinic acid concentration for the first harvest ranged from values close to $2.50 \mathrm{~g} / \mathrm{L}$ in CC and VK to values close to $1.65 \mathrm{~g} / \mathrm{L}$ in FA13, FA5, C35, and CL. The values of the M and V17 fruit were close to $2.00 \mathrm{~g} / \mathrm{L}$. During the following harvests, the amount of succinic acid decreased in all cases, but differently depending on rootstocks. Thus in the second harvest, the M and V17 fruit had the maximum values close to $1.80 \mathrm{~g} / \mathrm{L}$, while the minimum ones were obtained by FA13 and C35 with values close to $1.15 \mathrm{~g} / \mathrm{L}$. At the third harvest, the reduction in this acid was marked, and the values of FA13 and C35 were very low, with 0.41 and $0.10 \mathrm{~g} / \mathrm{L}$ respectively. The other fruit had values between 0.61 and $1.23 \mathrm{~g} / \mathrm{L}$ with no major differences among them. The rootstock effect was less marked during the first season. Even so, similarly to that observed during the second season, FA13 and C35 induced a lower succinic acid concentration in fruit.

In previous studies an effect of rootstock in organic acids was reported when 'Clemenules' fruit were harvested at the end of the season [11]. Nevertheless, the present study revealed that this effect can be harvest-dependent. 
A

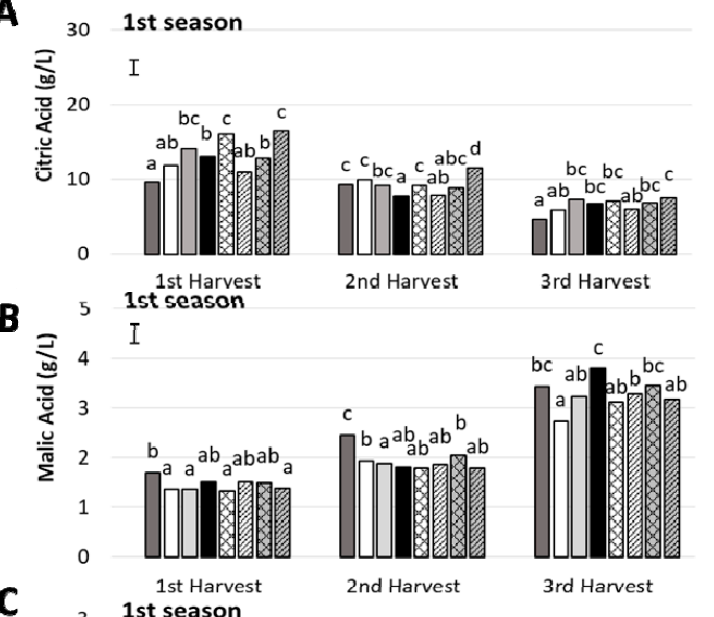

C
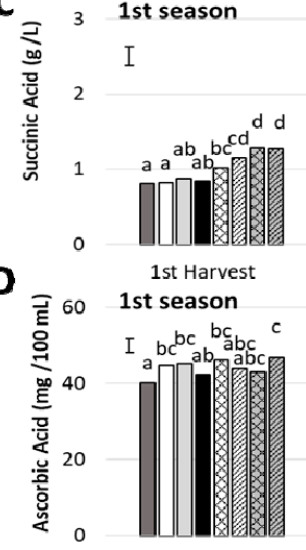

1st Harvest

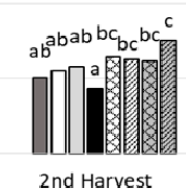

2nd Harvest

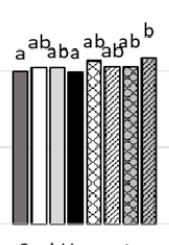

2nd Harvest
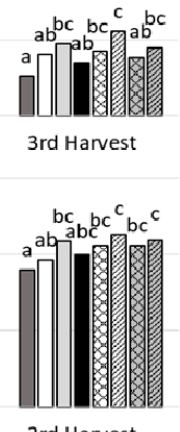
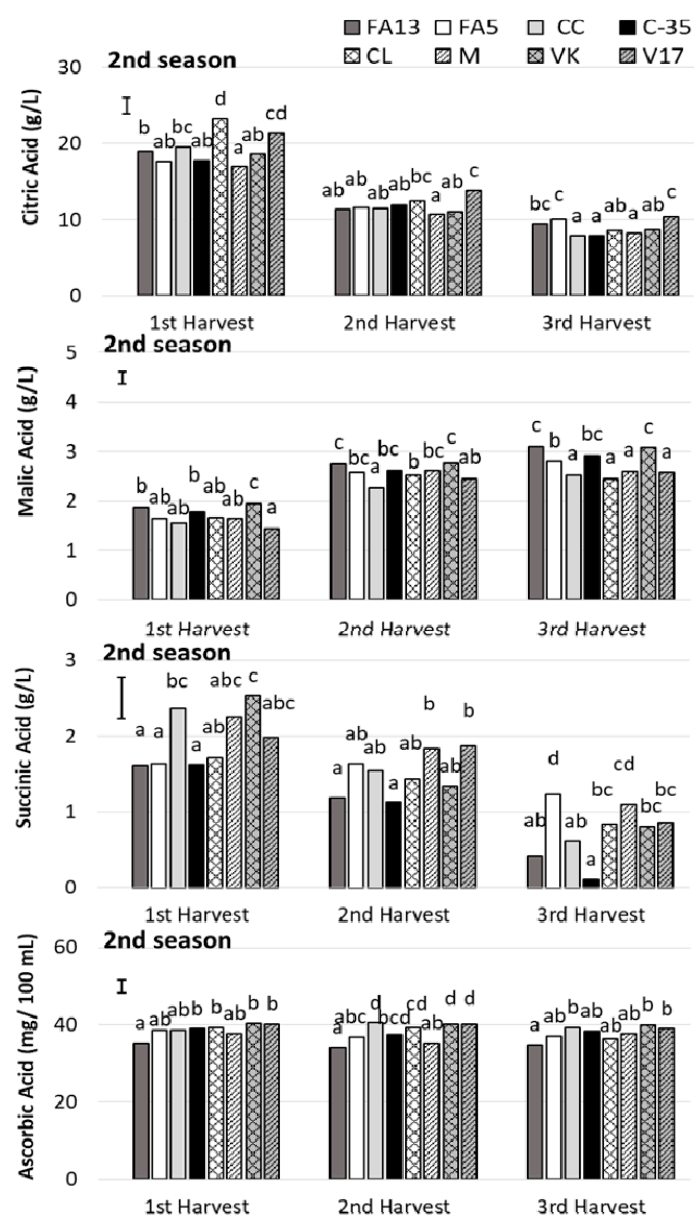

Figure 4. Organic acids (A: citric; B: malic; C: succinic) and vitamin C (D: ascorbic acid) of the 'Clemenules' mandarin grafted onto the eight studied rootstocks at three harvest times during two seasons. Vertical bar in each season represents the least significant difference (LSD) intervals ( $p \leq 0.05)$ (interaction harvest-rootstock). Different letters above bars indicate significant differences among rootstocks at each harvest time $(p \leq 0.05)$.

Citrus fruit is a well-known nutrient source of vitamin $C$ in dietary intake, which is the major antioxidant compound found in such fruit [36]. The range of the vitamin C levels obtained in the 'Clemenules' mandarin juices for all the rootstocks (Figure 4D) agree with the range previously reported for different citrus varieties [32]. The amounts of total ascorbic acid during the first season ranged from 46.92 to $35.98 \mathrm{mg} / 100 \mathrm{~mL}$, which were bigger than for the second season, when values were between 40.53 and $34.07 \mathrm{mg} / 100 \mathrm{~mL}$. During the first season, a slight decrease in ascorbic acid content was noted with harvest time, with no harvest effect detected during the second season (Table 2). A rootstock effect was found in the ascorbic acid content. The maximum ascorbic acid content was exhibited by CC, CL, M and V17 during the first season and by CC, VK and V17 during the second season. For both years, FA13 displayed the lowest ascorbic acid concentration. The study by Emmanouilidou and Kyriacou [14] into 'Lane late' and 'Delta' oranges grafted onto five rootstocks found that VK also induced the highest vitamin C amount, followed by CC and CL, respectively.

The major flavonoid detected in the 'Clemenules' mandarin juices for all the rootstocks was the flavanone hesperidin, followed by narirutin and didymin, respectively, which agrees with the existing literature [37,38].

Hesperidin was detected at concentrations between 11.98 and $14.14 \mathrm{mg} / 100 \mathrm{~mL}$ and from 11.52 to $15.32 \mathrm{mg} / 100 \mathrm{~mL}$, during the first and second season, respectively (Figure 5A). For the first season, no changes were observed with harvest time, but a decrease was noted for the last harvest during the second season (Table 2). No significant differences were observed among rootstocks during the first 
season. Nevertheless, during the second one, M, VK and V17 induced higher hesperidin contents when fruit were picked during the second and third harvests.

A

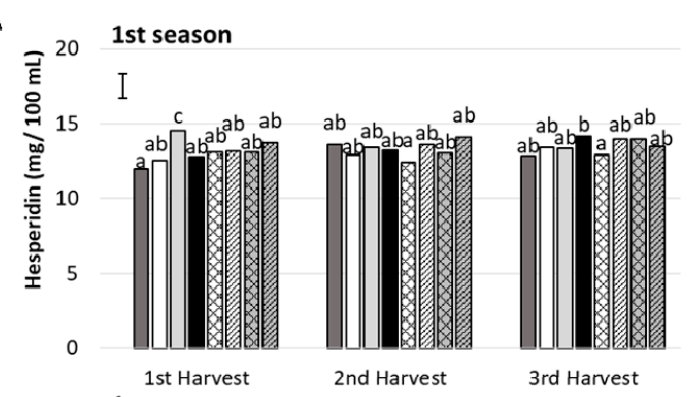

B

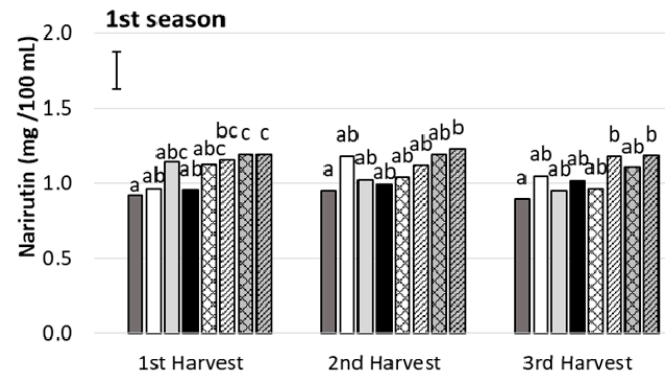

C

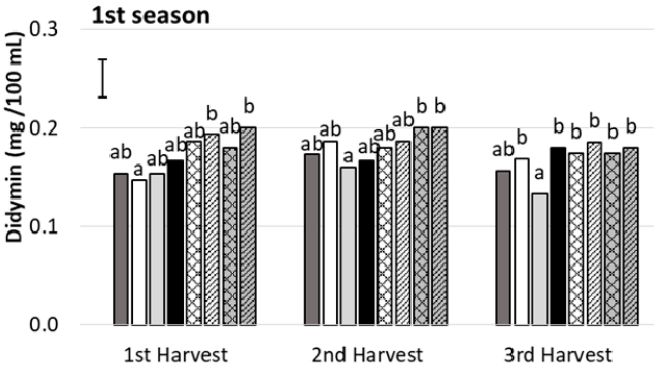

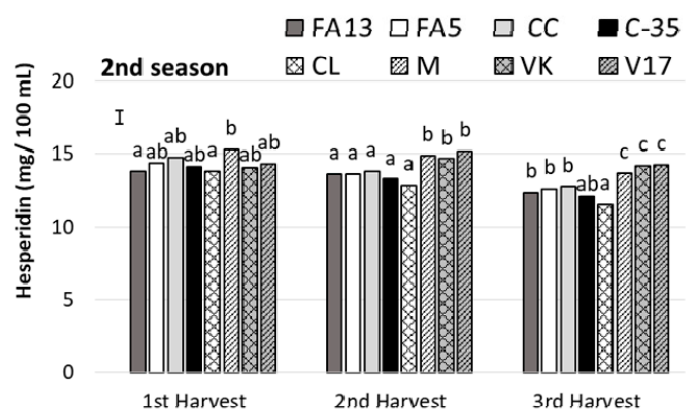
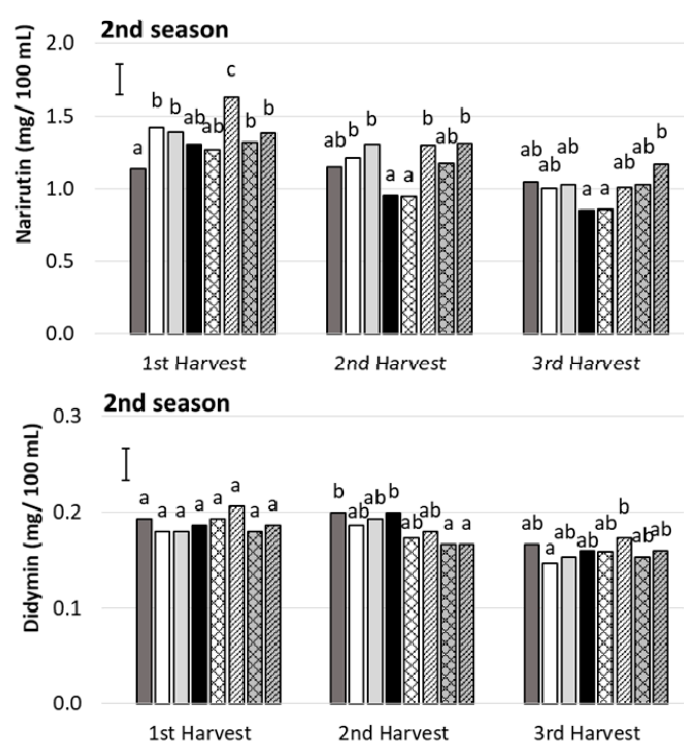

Figure 5. Flavonoids (A: hesperidin; B: narirutin; C: didymin) of the 'Clemenules' mandarin grafted onto the eight studied rootstocks at three harvest times (1st Harvest $(\mathrm{MI}=7)$, 2nd Harvest (30 days after $\mathrm{MI}=7$ ) and 3rd Harvest (60 days after MI $=7)$ ) during two seasons. Vertical bar in each season represents the least significant difference (LSD) intervals $(p \leq 0.05)$ (interaction harvest-rootstock). Different letters above bars indicate significant differences among rootstocks at each harvest time $(p \leq 0.05)$.

Narirutin content (Figure 5B) during the first season still showed no significant changes with harvest time, but differences among rootstocks (Table 2). M, VK and V17 were the rootstocks that induced the maximum values, while FA13 stood out for having less narirutin content. During the second season, a gradual decrease in narirutin content took place during harvests in all cases, except for FA13 whose values were similar throughout the study period and came close to $1.10 \mathrm{mg} / 100 \mathrm{~mL}$. The narirutin contents of the C35 and CL fruit dropped in the second harvest, and were the lowest values with $0.85 \mathrm{mg} / 100 \mathrm{~mL}$ in the third harvest.

Didymin was the minor determined flavanone (Figure 5C). For both seasons, its content ranged from 0.13 to $0.21 \mathrm{mg} / 100 \mathrm{~mL}$. During the second season, a significant decrease was detected for the last harvest, which was not observed during the first season (Table 2). A rootstock effect appeared during the first season, which was due to the lowest values for CC when comparing with the fruit from the other rootstocks. No rootstock influence was observed during the second season. 


\section{Conclusions}

The most remarkable result of this study was that the effect that rootstock could have on the different fruit quality parameters may be affected by their maturity stage. In order to obtain robust results, the importance of conducting studies in different seasons was clearly revealed.

The rootstock grafted onto 'Clemenules' mandarins can influence the optimal harvest time. This was the case of FA13 and C35, which induced a breakthrough in color change. This is an important aspect at the beginning of the season. Fruit can be harvested earlier and be submitted to shorter degreening treatment. FA13 and C35 induced the highest fruit firmness values. Regarding nutritional quality, FA13 and C35 induced the highest malic acid content, but the lowest succinic concentration. V17 stood out for being the rootstock that underwent the most marked color increase and the least acidity loss during harvest times, and was related to citric acid content. The lowest acidity loss exerted by V17 can be very useful to prolong the commercial period with fruit with high acidity at the end of the season. The fruit from this rootstock exhibited the highest glucose and fructose contents, as well as the highest vitamin C, hesperidin and narirutin contents. CC had the highest TSS content due to sucrose content. Similarly to V17, CC had high vitamin C content, but exhibited a tendency to present low flavonoid contents, particularly narirutin and didymin.

According to the results obtained in this study, the use of different rootstocks in the same agroclimatic location could allow an extension of the commercial season. In the case of 'Clemenules' mandarins, could be interesting to select FA13 and C35 to obtain fruit with high quality parameters earlier and V17 to have fruit with consumers acceptation at the end of this cultivar season.

Author Contributions: Conceptualization, A.S., J.M.; methodology, J.M., A.B. and A.S.; formal analysis, J.M., A.B. and P.N.; writing - original draft preparation, J.M. and A.S.; writing-review and editing, J.M., A.B. and A.S.; funding acquisition, A.S., A.B. All authors have read and agreed to the published version of the manuscript.

Funding: This study was co-financed by FEDER and European Social Funds.

Acknowledgments: The authors thank Anecoop S. Coop. for supplying the fruit herein used and its technical support.

Conflicts of Interest: The authors declare no conflict of interest.

\section{References}

1. Sharma, R.M.; Dubey, A.K.; Awasthi, O.P.; Kaur, C. Growth, yield, fruit quality and leaf nutrient status of grapefruit (Citrus paradisi macf.): Variation from rootstocks. Sci. Hortic. 2016, 210, 41-48. [CrossRef]

2. Yıldırım, F.; Yıldırım, A.N.; San, B.; Ercişli, S. The relationship between growth vigour of rootstock and phenolic contents in apple (malus $\times$ domestica). Erwerbs Obstbau 2016, 58, 25-29. [CrossRef]

3. Filho, F.D.A.A.; Espinoza-Núñez, E.; Stuchi, E.S.; Ortega, E.M.M. Plant growth, yield, and fruit quality of 'Fallglo' and 'Sunburst' mandarins on four rootstocks. Sci. Hortic. 2007, 114, 45-49. [CrossRef]

4. Castle, W.S. Rootstock as a fruit quality factor in citrus and deciduous tree crops. N. Z. J. Crop Hort. Sci. 1995, 23, 383-394. [CrossRef]

5. Machado, F.L.D.C.; Costa, J.D.P.D.; Teixeira, A.D.S.; Costa, J.M.C.D. The influence of rootstock and time of harvest on the fruit quality during storage of in two grapefruit cultivars. Acta Sci. Agron. 2015, 37, 339-346. [CrossRef]

6. Legua, P.; Martinez-Cuenca, M.R.; Bellver, R.; Forner-Giner, M.A. Rootstock's and scion's impact on lemon quality in southeast. Spain Int. Agrophys. 2018, 32, 325-333. [CrossRef]

7. McCollum, T.G.; Bowman, K.D.; Castle, W.S. Effects of rootstock on fruit quality and postharvest behavior of 'Marsh' grapefruit. Proc. Fla. State Hort. Soc. 2002, 115, 44-46.

8. Bassal, M.A. Growth, yield and fruit quality of 'Marisol' clementine grown on four rootstocks in Egypt. Sci. Hortic. 2009, 119, 132-137. [CrossRef]

9. Legua, P.; Forner, J.B.; Hernández, F.; Forner-Giner, M.A. Physicochemical properties of orange juice from ten rootstocks using multivariate analysis. Sci. Hortic. 2013, 160, 268-273. [CrossRef] 
10. Saini, M.K.; Capalash, N.; Kaur, C.; Singh, S.P. Comprehensive metabolic profiling to decipher the influence of rootstocks on fruit juice metabolome of Kinnow (C. nobilis $\times$ C. deliciosa). Sci. Hortic. 2019, 257, 108673. [CrossRef]

11. Legua, P.; Forner, J.B.; Hernández, F.; Forner-Giner, M.A. Total phenolics, organic acids, sugars and antioxidant activity of mandarin (Citrus clementina Hort. ex Tan.): Variation from rootstock. Sci. Hortic. 2014, 174, 60-64. [CrossRef]

12. Magwaza, L.S.; Mditshwa, A.; Tesfay, S.Z.; Opara, U.L. An overview of preharvest factors affecting vitamin C content of citrus fruit. Sci. Hortic. 2017, 216, 12-21. [CrossRef]

13. Cardeñosa, V.; Barros, L.; Barreira, J.C.; Arenas, F.; Moreno-Rojas, J.M.; Ferreira, I.C. Different Citrus rootstocks present high dissimilarities in their antioxidant activity and vitamins content according to the ripening stage. J. Plant Physiol. 2015, 174, 124-130. [CrossRef] [PubMed]

14. Emmanouilidou, M.G.; Kyriacou, M.C. Rootstock-modulated yield performance, fruit maturation and phytochemical quality of 'Lane Late' and 'Delta' sweet orange. Sci. Hortic. 2017, 225, 112-121. [CrossRef]

15. Yin, X.R.; Xie, X.L.; Xia, X.J.; Yu, J.Q.; Ferguson, I.B.; Giovannoni, J.J.; Chen, K.S. Involvement of an ethylene response factor in chlorophyll degradation during citrus fruit degreening. Plant J. 2016, 86, 403-412. [CrossRef]

16. Sumiasih, I.H.; Poerwanto, R.; Efendi, D.; Agusta, A.; Yuliani, S. $\beta$-Cryptoxanthin and Zeaxanthin Pigments Accumulation to Induce Orange Color on Citrus Fruits. IOP Conf. Ser. Mater. Sci. Eng. 2018, 299, 1-8. [CrossRef]

17. United Nations. UNECE Standard FFV-14: Citrus Fruit; United Nations: Geneva, Switzerland, 2018 ; p. 5.

18. Jimenez-Cuesta, M.; Cuquerella, J.; Martínez-Jávega, J. Determination of a color index for citrus fruit degreening. Proc. Int. Sot. Citric. 1981, 2, 750-753.

19. Bermejo, A.; Pardo, J.L.; Morales, J.; Cano, A. Comparative study of bioactive components and quality from juices of different mandarins: Discriminant multivariate analysis of their primary and secondary metabolites. Agric. Sci. 2016, 7, 341-351. [CrossRef]

20. Bermejo, A.; Pardo, J.; Cano, A. Murcott seedless: Influence of gamma irradiation on citrus production and fruit quality. Span. J. Agric. Res. 2012, 10, 768-777. [CrossRef]

21. Bermejo, A.; Pardo, J.; Cano, A. Influence of gamma irradiation on seedless citrus production: Pollen germination and fruit quality. Food Nutr. Sci. 2011, 2, 169-180. [CrossRef]

22. Sdiri, S.; Bermejo, A.; Aleza, P.; Navarro, P.; Salvador, A. Phenolic composition, organic acids, sugars, vitamin $\mathrm{C}$ and antioxidant activity in the juice of two new triploid late-season mandarins. Food Res. Int. 2012, 49, 462-468. [CrossRef]

23. Cano, A.; Bermejo, A. Influence of rootstock and cultivar on bioactive compounds in citrus peels. J. Sci. Food Agric. 2011, 91, 1702-1711. [CrossRef] [PubMed]

24. Pallottino, F.; Menesatti, P.; Lanza, M.C.; Strano, M.C.; Antonucci, F.; Moresi, M. Assessment of quality-assured Tarocco orange fruit sorting rules by combined physicochemical and sensory testing. J. Sci. Food Agric. 2012, 93, 1176-1183. [CrossRef] [PubMed]

25. Mazidi, M.; Sadrnia, H.; Khojastehpour, M. Evaluation of orange mechanical damage during packaging by study of changes in firmness. Int. Food Res. J. 2016, 23, 899-903.

26. Martínez-Jávega, J.M.; Cuquerella, J.; Salvador, A.; Monterde, A.; Navarro, P. Adecuación de tratamientos postcosecha a parámetros de recolección de mandarinas y naranjas de España. Red Interam. de Cítricos 2004, 24, 23-33.

27. Albrigo, L.G.; Carter, R.D. Carbohydrates: Composition, distribution, significance. In Citrus Science and Technology, 1st ed.; Nagy, S., Shaw, P.E., Matthew, K., Veldhuis, M.K., Eds.; Avi Publishing Company: Westport, CT, USA; California University: Oakland, CA, USA, 1977; Volume 2, pp. 74-93.

28. Castle, W.S.; Krezdorn, A.H. Soil water use and apparent root efficiencies of citrus trees on four rootstocks. J. Am. Soc. Hortic. Sci. 1977, 102, 403-406.

29. Syvertsen, J.P.; Graham, J.H. Hydraulic conductivity of roots, mineral nutrition, and leaf gas exchange of citrus rootstocks. J. Am. Soc. Hortic. Sci. 1985, 110, 865-869.

30. Ladanyia, M.S. Fruit Biochemistry. In Citrus Fruit: Biology, Technology and Evaluation, 1st ed.; Ladanyia, M.S., Ed.; Academic Press Elsevier: San Diego, CA, USA, 2008; pp. 125-190.

31. Julhia, L.; Belmin, R.; Meynard, J.M.; Pailly, O.; Casabianca, F. Acidity drop and coloration in clementine: Implications for fruit quality and harvesting practices. Front. Plant Sci. 2019, 10, 754. [CrossRef] 
32. Bermejo, A.; Cano, A. Analysis of nutritional constituents in twenty citrus cultivars from the Mediterranean area at different stages of ripening. Food Nutr. Sci. 2012, 3, 639-650. [CrossRef]

33. Sdiri, S.; Salvador, A.; Farhat, I.; Navarro, P.; Besada, C. Influence of postharvest handling on antioxidant compounds of Citrus fruits. In Citrus: Molecular Phylogeny, Antioxidant Properties and Medicinal Uses; Hayat, K., Ed.; Nova Publisher Inc.: New York, NY, USA, 2014; pp. 73-94.

34. Fabroni, S.; Romeo, F.V.; Rapisarda, P. Nutritional composition of clementine (citrus x clementina) cultivars. In Nutritional Composition of Fruit Cultivars, 1st ed.; Simmonds, M.S.J., Preedy, V.R., Eds.; Academic Press Elsevier: Amsterdam, The Netherlands, 2016; pp. 149-172. [CrossRef]

35. Distefano, G.; Las Casas, G.; Caruso, M.; Todaro, A.; Rapisarda, P.; La Malfa, S.; Gentile, A.; Tribulato, E. Physiological and molecular analysis of the maturation process in fruits of clementine mandarin and one of its late-ripening mutants. J. Agric. Food Chem. 2009, 57, 7974-7982. [CrossRef]

36. Yang, X.Y.; Xie, J.X.; Wang, F.F.; Zhong, J.; Liu, Y.Z.; Li, G.H.; Peng, S.A. Comparison of ascorbate metabolism in fruits of two citrus species with obvious difference in ascorbate content in pulp. J. Plant Physiol. 2011, 168, 2196-2205. [CrossRef] [PubMed]

37. Tripoli, E.; La Guardia, M.; Giammanco, S.; Di Majo, D.; Giammanco, M. Citrus flavonoids: Molecular structure, biological activity and nutritional properties: A review. Food Chem. 2007, 104, 466-479. [CrossRef]

38. Khan, M.K.; Dangles, O. A comprehensive review on flavanones, the major citrus polyphenols. J. Food Compos. Anal. 2014, 33, 85-104. [CrossRef]

(C) 2020 by the authors. Licensee MDPI, Basel, Switzerland. This article is an open access article distributed under the terms and conditions of the Creative Commons Attribution (CC BY) license (http://creativecommons.org/licenses/by/4.0/). 